\title{
Excellentie in het hoger onderwijs: Selectie, effectiviteit en uitstralingseffecten
}

Citation for published version (APA):

van Broekhoven, K., Huijts, T., Isendam, M., Jacobs, M., Kolster, R., Leest, B., Meng, C., Westerheijden, D., \& Wolbers, M. (2020). Excellentie in het hoger onderwijs: Selectie, effectiviteit en uitstralingseffecten. ROA. ROA Reports No. 001S https://doi.org/10.26481/umarep.2020001S

Document status and date:

Published: 06/04/2020

DOI:

10.26481/umarep.2020001S

Document Version:

Publisher's PDF, also known as Version of record

\section{Please check the document version of this publication:}

- A submitted manuscript is the version of the article upon submission and before peer-review. There can be important differences between the submitted version and the official published version of record.

People interested in the research are advised to contact the author for the final version of the publication, or visit the DOI to the publisher's website.

- The final author version and the galley proof are versions of the publication after peer review.

- The final published version features the final layout of the paper including the volume, issue and page numbers.

Link to publication

\footnotetext{
General rights rights.

- You may freely distribute the URL identifying the publication in the public portal. please follow below link for the End User Agreement:

www.umlib.nl/taverne-license

Take down policy

If you believe that this document breaches copyright please contact us at:

repository@maastrichtuniversity.nl

providing details and we will investigate your claim.
}

Copyright and moral rights for the publications made accessible in the public portal are retained by the authors and/or other copyright owners and it is a condition of accessing publications that users recognise and abide by the legal requirements associated with these

- Users may download and print one copy of any publication from the public portal for the purpose of private study or research.

- You may not further distribute the material or use it for any profit-making activity or commercial gain

If the publication is distributed under the terms of Article $25 \mathrm{fa}$ of the Dutch Copyright Act, indicated by the "Taverne" license above, 
Maastricht University

$\$$ ROA

\section{Excellentie in het hoger onderwijs: Selectie, effectiviteit en uitstralingseffecten}

Kim van Broekhoven

Tim Huijts

Marieke Isendam

Madelon Jacobs

Renze Kolster

Bianca Leest

Christoph Meng

Don Westerheijden

Maarten Wolbers

\section{ROA Samenvatting}

ROA-R-2020/1S

Researchcentrum voor Onderwijs en Arbeidsmarkt | ROA Research Centre for Education and the Labour Market / ROA 
Colofon

(c) Researchcentrum voor Onderwijs en Arbeidsmarkt (ROA). Niets uit deze uitgave mag op enige manier worden verveelvoudigd zonder voorafgaande schriftelijke toestemming van de directeur van het ROA.

\section{Researchcentrum voor Onderwijs en Arbeidsmarkt}

Postbus 616

6200 MD Maastricht

$\mathrm{T}+31433883647$

$\mathrm{F}+31433884914$

secretary-roa-sbe@maastrichtuniversity.nl

www.roa.nl

School of Business and Economics

Maastricht University

\section{Vormgeving}

ROA secretariaat, Maastricht

ISBN: 978-90-5321-590-6

februari 2020

\section{NRO}

Dit project is gefinancierd door het NRO.

NRO projectnummer: 405-15-604

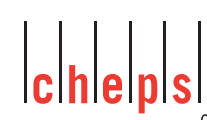

Center for

Higher Education Policy Studies
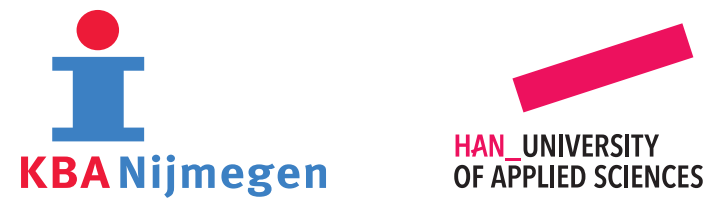

HAN_UNIVERSITY OF APPLIED SCIENCES 


\section{INLEIDING}

In het afgelopen decennium is binnen het hoger onderwijs in Nederland geleidelijk meer aandacht gekomen voor verschillen tussen studenten en de vraag hoe het onderwijs daarop goed kan inspelen. Door differentiatie - het bieden van variëteit in de inhoud, de vorm en het niveau - kan het onderwijs beter op studenten worden afgestemd. Excellentieonderwijs is onderwijs gericht op studenten die zich in het reguliere onderwijs te weinig uitgedaagd voelen. Hiermee wordt het vizier scherper dan voorheen gericht op studenten die meer dan gemiddeld gemotiveerd en getalenteerd zijn.

De ontwikkeling van excellentieprogramma's aan de hogescholen en universiteiten werd gestimuleerd door het Sirius-subsidieprogramma. Dit programma liep van 2008 tot 2014 en had een budget van 60 miljoen euro. Het excellentieonderwijs heeft sindsdien opgang gemaakt in het gehele Nederlandse hoger onderwijs. Na het beëindigen van het Siriusprogramma spraken veel hogeronderwijsinstellingen de intentie uit om het excellentieonderwijs te blijven voortzetten, in het 'Manifest voor excellentieonderwijs van de toekomst.' Het Ministerie van OCW heeft deze intentie ondersteund met het onderzoeksprogramma Excellentie van het Nationaal Regieorgaan Onderwijsonderzoek (NRO). Immers, ondanks dat het excellentieonderwijs breed ingang heeft gevonden in het Nederlandse hoger onderwijs, is er nog maar weinig bekend over de opbrengsten en effecten ervan voor studenten en onderwijsinstellingen.

In de periode van medio oktober 2015 tot december 2019 hebben wij onderzoek gedaan naar de effecten van excellentieonderwijs in het Nederlandse hoger onderwijs, binnen het project 'Excellentie in het hoger onderwijs: selectie, effectiviteit en uitstralingseffecten'. Dit onderzoek was onderdeel van het onderzoeksprogramma Excellentie van het NRO. Het voorliggende document is een korte overkoepelende samenvatting van dit onderzoek. Meer gedetailleerde rapportages over het onderzoek zijn beschikbaar in drie separate rapporten (nl. 'Excellentieonderwijs: selectie van studenten en individuele effecten'; 'Onderwijskeuzes en employability; buitenlandervaring, bestuurservaring en excellentieonderwijs in de werving door werkgevers'; en 'Uitstralingseffecten van excellentieonderwijs; van innovatie naar uitstraling'). In deze overkoepelende samenvatting beschrijven we de achtergrond, aanleiding en opzet van het onderzoek, en vervolgens de belangrijkste conclusies, aanbevelingen en aandachtspunten die uit het onderzoek voortgevloeid zijn. Excellentieonderwijs komt voor onder benamingen zoals honoursprogramma's, talentenprogramma's, 'talent academies' et cetera. Voor de leesbaarheid (en in lijn met het onderzoeksprogramma Excellentie van het NRO) hanteren we in deze samenvatting de termen 'excellentieonderwijs' en 'honoursstudenten'.

\section{ACHTERGROND EN AANLEIDING VAN HET ONDERZOEK}

Niet alleen in visie, maar ook in naamgeving, organisatie, vormgeving, positie ten opzichte van de reguliere opleiding en disciplinaire oriëntatie bestaat er een grote 
variëteit in het excellentieonderwijs. Ondanks deze variëteit kampen excellentieprogramma's wel met een aantal gemeenschappelijke uitdagingen. Een van de uitdagingen waar excellentieprogramma's mee worstelen is hoe ze de selectie van studenten moeten vormgeven. Die procedures verschillen niet alleen tussen instellingen, maar ook binnen instellingen. Sommige programma's gebruiken een aantal formele criteria, zoals het gemiddeld studiecijfer. Andere kijken vooral naar de motivatie, zoals blijkt uit een brief of uit gesprekken. Er is echter weinig bekend over de effectiviteit van die selectieinstrumenten: welke factoren spelen een rol bij de selectie, welke factoren bepalen of studenten die deelnemen aan een excellentieprogramma het ook succesvol afronden, en hoe kan de effectiviteit van die selectie verbeterd worden?

Een gerelateerd punt is dat er weinig zicht is op de individuele effecten van excellentieprogramma's. Uit eerder verricht onderzoek naar de evaluatie van het Sirius-programma blijkt dat afgestudeerden van excellentieprogramma's een hoger eindcijfer halen en positiever oordelen over de opleiding. In die zin lijken excellentieprogramma's toegevoegde waarde te hebben. De geselecteerde studenten zijn echter een bijzondere groep. Ze zijn, zo toonde eerder onderzoek aan, meer gemotiveerd en hebben meer cognitieve vaardigheden dan studenten die niet in de excellentieprogramma's zitten. Dat maakt dat deze studenten alleen daarom al meer studiesucces hebben. De vraag is wat het separate effect van excellentieprogramma's is als we controleren voor deze selectie-effecten. Daarnaast is er nog veel onduidelijkheid over de leeruitkomsten van excellentieonderwijs in bredere zin. Bij leeropbrengsten ligt het voor de hand om in eerste instantie aan studieresultaten te denken, maar vaak worden ook meer generieke vaardigheden zoals creativiteit, doorzettingsvermogen en kritisch denken aan excellente studenten toegedicht. De vraag is echter of studenten op deze vaardigheden geselecteerd worden voor deelname aan excellentieprogramma's, of dat studenten tijdens hun deelname aan excellentieprogramma's een sterkere groei in deze vaardigheden doormaken dan studenten in reguliere programma's.

De individuele effecten kunnen niet alleen de leeruitkomsten betreffen, maar ook de effecten op employability. Oftewel, hebben afgestudeerden die een excellentieprogramma hebben doorlopen meer kans op de arbeidsmarkt? In het onderzoek uit 2015 werd geconcludeerd dat werkgevers nog nauwelijks bekend zijn met het concept van excellentieonderwijs in het hoger onderwijs. Tegelijkertijd weten we wel dat veel studenten juist ervoor kiezen om excellentieonderwijs te doen vanwege een aangenomen positief effect op de arbeidsmarkt. Ook dit roept vragen op: weten werkgevers inmiddels beter wat excellentieonderwijs is, en geeft het de studenten daadwerkelijk een streepje voor?

Ten slotte, veel instellingen streven ernaar om het excellentieonderwijs een proeftuin te laten zijn waar geëxperimenteerd mag worden met onderwijs en de manier waarop dat aangeboden en georganiseerd wordt. Instellingen verwachten zo dat investeringen in het excellentieonderwijs zich doorvertalen naar het reguliere onderwijs, de gehele organisatie, en naar de buitenwereld. Er worden dus positieve uitstralingseffecten 
van excellentieonderwijs verwacht. Maar gebeurt dit, en zo ja in welke mate, en welke sturingsmechanismen kunnen instellingen inzetten om uitstralingseffecten te bereiken en te vergroten?

\section{OPZET VAN HET ONDERZOEK: ONDERZOEKSVRAGEN EN ONDERZOEKSMETHODEN}

Om meer zicht te krijgen op de hierboven beschreven witte vlekken in onze kennis over excellentieprogramma's, richt dit onderzoek zich op de individuele effecten van excellentieprogramma's, de wijze waarop instellingen erin slagen 'de beste' studenten hieraan deel te laten nemen en uit te dagen om nog beter te presteren, en de vraag wat de uitstralingseffecten uit excellentieonderwijs zijn en hoe deze meer structureel ingebed kunnen worden. Deze verschillende aspecten zijn nader uitgewerkt en verder onderzocht in drie deelprojecten.

Het eerste deelproject richt zich op de vraag of bij de selectie van studenten een goede match plaatsvindt tussen aanbod en type student. Daarbij gaat het zowel om het in kaart brengen van het selectieproces en de instrumenten die daarbij gebruikt worden, als om het identificeren van factoren waarop studenten die deelnemen aan excellentieprogramma's zich onderscheiden van studenten die niet deelnemen en het toetsen van factoren die voorspellend zijn voor hun succes in het excellentieprogramma.

Hiermee samenhangend richt het tweede deelproject zich op de individuele effecten van excellentieprogramma's. Hierbij gaat het onder meer om de vraag of de invoering van excellentieprogramma's leidt tot hogere prestaties (zowel cognitief als non-cognitief) en of dit daadwerkelijk aan het programma kan worden toegeschreven of aan het feit dat 'betere' studenten nu eenmaal beter presteren. Dit onderzoek draagt bij aan de huidige kennis over de individuele opbrengsten van deelname aan excellentieprogramma's door het gebruik van een representatieve controlegroep, door te kijken naar verschillende uitkomstmaten (o.a. kritische denkvaardigheden, creativiteit, leiderschap en politieke betrokkenheid) en verklarende variabelen, en door de ontwikkeling van studenten over een periode van ongeveer twee jaar te vergelijken door het gebruik van zowel een beginmeting en een eindmeting bij twee cohorten. Hierdoor kan de groei die studenten in regulier onderwijs en in excellentieprogramma's doormaken worden vastgesteld en vergeleken.

Naast deze focus op de individuele ontwikkeling van studenten richt het tweede deelproject zich ook op de meerwaarde op de arbeidsmarkt van het volgen van een excellentieprogramma. Van hoger onderwijs wordt in toenemende mate verwacht dat het studenten voorbereidt op de arbeidsmarkt. Het moet studenten employable maken (oftewel, studenten in staat stellen om werk te vinden en te behouden). Vele factoren spelen mee in het employable maken van studenten; zo mogelijk ook onderwijskeuzes die studenten kunnen maken tijdens hun studie. Wij richten ons op de keuzes om een 
buitenlandervaring, bestuurservaring of excellentieonderwijs op te doen tijdens een universitaire studie. De relatie tot employability is onderzocht door werkgevers te laten reflecteren op de rol van deze onderwijskeuzes in wervingsoverwegingen.

Het derde deelproject richt zich op de uitstralingseffecten van excellentieprogramma's op het reguliere onderwijs en de reguliere organisatie. In de evaluatie van het Siriusprogramma werd de indruk gewekt dat er mogelijk bredere positieve uitstralingseffecten zijn op het reguliere onderwijs en op de organisatie als geheel. In het derde deelproject is daarop dieper ingegaan in een aantal casestudies bij universiteiten en hogescholen.

Al met al zijn in de drie deelprojecten van dit onderzoek de volgende centrale onderzoeksvragen aan bod gekomen:

1. Hoe kan de selectie van kandidaten voor excellentieprogramma's verbeterd worden en welke instrumenten geven de beste match tussen persoon en programma?

2. Wat is de individuele toevoegende waarde van deelname aan excellentieprogramma's voor studenten op zowel cognitieve als non-cognitieve vaardigheden?

3. In welke mate en op welke wijze beïnvloeden gemaakte onderwijskeuzes de employability van recent universitair afgestudeerden blijkend uit de wervingsoverwegingen van werkgevers?

4. Wat zijn de uitstralingseffecten van excellentieprogramma's op de reguliere organisatie en op het reguliere onderwijs?

5. Welke sturingsmechanismen kan een instelling inzetten om innovaties uit excellentieprogramma's te gebruiken in de organisatie en binnen het reguliere onderwijs?

In ons onderzoek hebben we diverse methoden voor dataverzameling en data-analyse gebruikt om deze onderzoeksvragen te beantwoorden. Voor beantwoording van de onderzoeksvragen rondom selectie en effectiviteit hebben we zes dataverzamelingsmethoden gebruikt: (a) afname van (online) vragenlijsten en testen bij studenten; (b) verzamelen van administratieve gegevens bij studentenadministraties; (c) opvragen van selectie-oordelen bij selecteurs van excellentieprogramma's; (d) interviews met selecteurs van excellentieprogramma's; (e) afname van online vragenlijst met vignetten bij selecteurs; en (f) interviews met 20 HR-professionals. De hiermee verkregen data zijn vervolgens geanalyseerd middels diverse kwantitatieve en kwalitatieve analysetechnieken. De onderzoeksvragen met betrekking tot uitstralingseffecten en sturingsmechanismen zijn onderzocht aan de hand van een uitgebreide documentanalyse en digitale vragenlijsten en interviews met 29 respondenten (beleidsmedewerkers, opleidingsdirecteuren, excellentiecoördinatoren, docenten en studenten) van drie universiteiten en twee hogescholen. 


\section{BELANGRIJKSTE CONCLUSIES}

\subsection{Selectie van studenten voor excellentieprogramma's}

Bij op een na alle onderzochte excellentieprogramma's vormt de schriftelijke sollicitatie de opmaat tot een mondelinge selectieprocedure die uit een of twee fasen bestaat. Voorselectie op basis van de schriftelijke fase is regelmatig alleen een theoretische mogelijkheid omdat het aantal aanmeldingen niet of nauwelijks het aantal beschikbare plaatsen overstijgt en selecteurs studenten een kans willen geven om in de mondelinge fase hun geschiktheid voor het programma aan te tonen. Selectiecriteria met een vastgestelde norm bestaan in de onderzochte programma's alleen op het vlak van studievoortgang (propedeuse behaald) en studieresultaten (een minimum gemiddelde), maar deze normen worden in de regel niet hard gehanteerd. Voor andere selectiecriteria die worden gebruikt zijn geen normen vastgesteld. Het betreft in de regel eigenschappen en competenties die men lastig te objectiveren en kwantificeren acht.

Met betrekking tot de eerste onderzoeksvraag concluderen we dat de studenten die deelnamen aan excellentieprogramma's al bij de start van het programma hoger scoorden op de meeste cognitieve en non-cognitieve uitkomstmaten dan studenten in het regulier onderwijs. Wanneer er wordt gekeken naar de kans om deel te nemen aan excellentieprogramma's laten de resultaten zien dat kritisch denkvermogen en studieresultaten belangrijke factoren zijn om de deelname te voorspellen. Daarnaast is de kans op deelname aan excellentieprogramma's hoger voor studenten die meer intrinsiek en extrinsiek gemotiveerd en zorgvuldiger zijn. Ons onderzoek laat verder zien dat geen van de relevant geachte factoren een duidelijk effect hebben op de kans op succesvolle afronding van excellentieprogramma's. Uit de resultaten van deze analyses komt wel naar voren dat honoursstudenten die meer uren per week werken naast hun studie een kleinere kans hebben op succesvolle afronding van het excellentieprogramma.

In het vignettenonderzoek dat gehouden is onder selecteurs van excellentieprogramma's komt sterk naar voren dat selecteurs gedurende het selectieproces de 'beste' studenten willen aannemen. Voor zowel hbo als wo geldt dat hogere cijfers en meer extracurriculaire ervaringen zoals buitenlandervaring, studiegerelateerde bijbaan en vrijwilligerswerk positief bijdragen aan de kans om aangenomen te worden voor excellentieprogramma's. Daarnaast spelen motivatie, denkvermogen, doorzettingsvermogen, maatschappelijke betrokkenheid en creativiteit een belangrijke rol in het aannemen van studenten.

\subsection{Individuele toevoegende waarde van deelname aan excellentieprogramma's}

De belangrijkste conclusie die getrokken kan worden met betrekking tot de tweede onderzoeksvraag is dat honoursstudenten die gedurende hun bachelor hebben deelgenomen aan excellentieprogramma's zich zowel op cognitieve en non-cognitieve uitkomstmaten positief hebben ontwikkeld. Reguliere studenten maken echter een soortgelijke positieve groei door. Honoursstudenten verschillen daarin dus niet significant van studenten in het regulier onderwijs. Dit betekent overigens niet noodza- 
kelijkerwijs dat honoursstudenten nadeel ondervinden van deelname aan excellentieprogramma's. Zo lijkt deelname aan excellentieprogramma's niet ten koste te gaan van bijvoorbeeld studieresultaten: honoursstudenten blijven gedurende hun gehele bachelorprogramma hogere studieresultaten behalen dan reguliere studenten. Over het algemeen halen honoursstudenten hogere scores dan reguliere studenten op alle uitkomstmaten, waarbij de voornaamste verklaring is dat honoursstudenten al bij de start van de excellentieprogramma's beter op de meeste cognitieve en non-cognitieve uitkomstmaten scoorden dan studenten in het regulier onderwijs. Dit suggereert dat de belangrijkste verschillen tussen beide groepen voortkomen uit selectie van studenten voor excellentieprogramma's.

\subsection{Onderwijskeuzes en employability van recent afgestudeerden}

Van de verschillende onderwijskeuzes die met de HR-professionals besproken zijn buitenlandervaring, bestuurservaring of excellentieonderwijs - zijn de werkgevers het minst bekend met excellentieonderwijs. Het ligt voor de hand dat dit te maken heeft met (1) de - in Nederland - nog relatief jonge geschiedenis van deze onderwijskeuze, en (2) het relatief summiere aantal deelnemers aan deze onderwijskeuze.

Uit de interviews met HR-professionals komt naar voren dat onderwijskeuzes een rol spelen in wervingsoverwegingen van werkgevers aangaande recent universitair afgestudeerden. Dit gaat op voor alle onderwijskeuzes, waarbij relatief gezien een bestuurservaring het meeste voordeel geeft. Excellentieonderwijs lijkt met name een rol te spelen in functies bij de overheid, terwijl bestuurlijke ervaring wordt geprefereerd door de private sector. Voor de prestigieuze startersfuncties, zoals traineeships, zijn alle onderwijskeuzes relevant. Ongeacht het voordeel in de werving kan verwacht worden dat in de selectiefase vragen worden gesteld over de gemaakte onderwijskeuze. Een kandidaat moet kunnen uitleggen waarom er een specifieke onderwijskeuze is gemaakt, wat er is geleerd, en hoe de ervaring heeft bijgedragen aan de persoonlijke ontwikkeling. Terugkijkend op het wervingsproces, is te stellen dat zeker in het geval dat profielen van kandidaten gelijk zijn, vaak wordt gekeken naar onderwijskeuzes. Deze worden ook gebruikt om snel veel cv's te screenen.

Dit onderzoek geeft verder aanleiding om te veronderstellen dat bij de drie onderwijskeuzes verschillende mechanismen een verklaring kunnen geven. De werkgevers associëren bij een bestuurservaring vooral concrete vaardigheden die noodzakelijk zijn voor het uitvoeren van de functie waarvoor geworven wordt (bijvoorbeeld leiderschapsvaardigheden die noodzakelijk zijn in traineeshipposities). Excellentieonderwijs daarentegen lijkt vooral meer te zeggen over de persoon die dit gedaan heeft, bijvoorbeeld intelligentie, doorzettingsvermogen en ambitie, en minder over wat de persoon exact kan. De in de literatuur over excellentieonderwijs genoemde vaardigheden, zoals creativiteit, worden niet of minder vaak genoemd door de respondenten. 


\subsection{Uitstralingseffecten van excellentieprogramma's}

Het overgrote deel van de respondenten geeft aan dat het excellentieonderwijs functioneert als proeftuin voor onderwijs of organisatorische innovaties. Excellentieonderwijs is slechts een van de bronnen van innovaties, andere - zoals initiatieven van individuele docenten - worden door de respondenten vaak als belangrijker ingeschat. Dit betekent dat het excellentieonderwijs functioneert als proeftuin, maar dat het niet de voornaamste bron is voor onderwijsinnovatie.

Het excellentieonderwijs leent zich voor het experimenteren met bestaande en nieuw ontwikkelde innovaties. Bij de casestudies zijn we vijf typen innovaties tegengekomen:

- Onderwijsconcepten / didactische methoden, zoals 'student-driven learning' en 'flipped classroom'.

- Toetsvormen, zoals een vrijere manier van toetsing en open beoordelingskaders.

- Inhoud van onderwijs, zoals inter-/multidisciplinair onderwijs en onderwijs gestoeld op maatschappelijke relevantie,

- Tools voor onderwijs, zoals personal development plans en een matching tool voor groepsopdrachten.

- Organisatorisch, zoals een kwaliteitszorgsysteem en common rooms.

De innovaties zijn vooral genoemd door de medewerkers die er directe ervaringen mee hebben. De hogeronderwijsinstellingen op centraal niveau lijken weinig zicht te hebben op alle innovaties die worden ontwikkeld en die mogelijk uitgestraald kunnen worden. Er is op instellingsniveau dus weinig zicht op de mate waarin het excellentieonderwijs de proeftuinfunctie realiseert. Wij observeren dat het uitstralingsproces voornamelijk gaat via docenten, oftewel op een directe manier. Er zit weinig sturing op het bereiken van uitstraling; het moet vooral van onderop (bottom-up) komen. In het uitstralingsproces hebben beleidsmakers vooral een faciliterende rol. Ze kunnen docenten verbinden, bijvoorbeeld door het organiseren van bijeenkomsten of netwerken.

In antwoord op de vierde centrale onderzoeksvraag concluderen we dat uitstalingseffecten die in vrijwel alle instellingen waargenomen worden te maken hebben met: (primaire uitstralingseffecten) didactiek, werk- en begeleidingsvormen, onderwijsvormgeving met inbreng van studenten, honoursdocenten die in het reguliere onderwijs (blijven) lesgeven, honoursstudenten in regulier onderwijs, (secundaire uitstralingseffecten) relatiestructuren, (tertiaire uitstralingseffecten) betere reputatie van instelling en zichtbaarheid van de organisatie. Kortom, het hebben van excellentieonderwijs heeft daadwerkelijk uitstralingseffecten op onderwijs en op de organisatie. Wel past bescheidenheid over de mate van impact van excellentieonderwijs op het reguliere onderwijs. Het is moeilijk om fundamentele veranderingen enkel toe te schrijven aan excellentieonderwijs.

Kijkend naar de vijfde onderzoeksvraag is in het algemeen te stellen dat sturingsmechanismen zelden met het oog op uitstralingseffecten worden ingezet. De ingezette 
sturingsmechanismen hebben vooral te maken met het creëren van condities waarin mogelijk uitstralingseffecten kunnen ontstaan. Deze observatie is verwonderlijk, drie van de vijf instellingen geven immers in beleidsstukken aan dat het excellentieonderwijs behoort te functioneren als proeftuin voor onderwijsinnovatie, maar concrete beleidsinstrumenten worden aan die doelstelling niet of nauwelijks gekoppeld. Om te sturen is strategische inbedding van het excellentieonderwijs van belang, bijvoorbeeld via centrale coördinatie van excellentieonderwijs en toewijding van het instellingsbestuur. Wat opvalt - gezien de belangrijke rol van docenten in het uitstralingsproces - is dat de gemeenschap van honoursdocenten weinig aandacht krijgt, terwijl dit juist iets zou zijn om centraal te organiseren.

\section{AANBEVELINGEN EN AANDACHTSPUNTEN}

Op basis van ons onderzoek doen we diverse aanbevelingen voor beleidsmakers en beleidsuitvoerders op het gebied van excellentieonderwijs, en stippen we enkele aandachtspunten aan. Tot slot presenteren we enkele aanbevelingen voor studenten. De aanbevelingen en aandachtspunten voor de diverse doelgroepen zijn als volgt:

\section{Beleidsmakers:}

- De invloed van het inkomens- en opleidingsniveau van ouders op de kans om voor een excellentieprogramma te worden geselecteerd geeft aanleiding tot reflectie op de toegankelijkheid van excellentieprogramma's voor studenten met verschillende achtergronden.

- Honoursstudenten onderscheiden zich door een hoge extrinsieke motivatie. Daar kun je als programma op inspelen (onderscheidende kwalificatie, selectief programma), maar het kan ook het risico geven dat je studenten aantrekt die vooral gericht zijn op cv-building.

- Belangrijk is om gezamenlijk - docenten, coördinatoren, selecteurs, studenten scherp te krijgen wat de leerdoelen zijn binnen het aangeboden programma. Waar willen we de groei zien, wat zijn de verwachtingen, wat willen studenten eruit halen? Excellentietrajecten zijn bij uitstek geschikt om een leertraject op maat te bieden.

- Vergeleken met buitenlandervaring en bestuurservaring, weten nog relatief weinig werkgevers wat excellentieonderwijs is. Dit betekent dat er meer aan promotie gedaan kan worden. Zorg dat externe stakeholders weten wat excellentieonderwijs is, wat de voordelen zijn, en wat het zegt over deelnemende studenten.

- Om de onderwijskeuzes van onderscheidende waarde te laten zijn, adviseren werkgevers om excellentieonderwijs vooral selectief en dus exclusief te houden.

- Met betrekking tot de onderscheidende waarde, de promotie en de extrinsieke motivatie, kan geadviseerd worden om studenten die excellentieonderwijs afronden een onderscheidende kwalificatie te (blijven) geven.

- Merk excellentieonderwijs aan als proeftuin in visie en beleid, en monitor de behaalde uitstralingseffecten. 
- Zorg dat de proeftuin organisatorisch ondersteund wordt, bijvoorbeeld door een organisatie- en onderwijskundig gerichte ondersteunende dienst. Zo'n dienst kan helpen in de verspreiding van innovaties, bijvoorbeeld door de vaste kern te vormen van een netwerk van docenten.

- Commitment van beleidsmakers en bestuurders voor uitstralingseffecten uit het excellentieonderwijs is belangrijke steun ervoor en versterkt andere instrumenten.

- Aansluiting in didactische vormgeving tussen regulier en excellentieonderwijs is belangrijk voor het succes van uitstralingseffecten. Dit is bevorderlijk voor de weging (compatibility) van innovaties.

- Zorg dat het excellentieonderwijs vernieuwend blijft.

- Zorg bij nieuw-en herbouw of herinrichting van gebouwen dat er een aparte ruimte wordt bestemd voor honoursstudenten en -docenten. Dit draagt bij aan communityvorming en aan de zichtbaarheid.

- Vergroot de betrokkenheid van de coördinatoren van het excellentieonderwijs (bijvoorbeeld een Honours Dean) bij andere gremia die over onderwijs(-vernieuwing) gaan.

\section{Beleidsuitvoerders:}

- Selecteurs willen de beste studenten die tot de top $25 \%$ behoren en zichzelf volop naast hun studie ontplooien, maar uit onze resultaten blijkt dat honoursstudenten die meer werken naast hun studie een kleinere kans hebben om het excellentieprogramma succesvol af te ronden.

- Uitstraling wordt bevorderd door honoursdocenten die een dubbelfunctie hebben, bijvoorbeeld als docenten in het reguliere onderwijs en/of via hun betrokkenheid bij bestuur (bijvoorbeeld opleidingsdirecteur of deelname aan stuurgroepen).

- Betrek het excellentieonderwijs in docentprofessionaliseringtrajecten.

- Vergroot de deelname van docenten, bijvoorbeeld door betrokkenheid bij excellentieonderwijs meer te erkennen, door docenten voor een specifiek vak aan te trekken en door een gemeenschap van honoursdocenten te creëren.

- Zorg voor vertegenwoordiging van één of meer docenten uit zo veel mogelijk verschillende reguliere studieprogramma's in het excellentieonderwijs.

- Zorg voor externe peer reviews van het excellentieonderwijs (bijvoorbeeld uit het Sirius netwerk) om zo kwaliteitszorg en -ontwikkeling te stimuleren.

- Verbeter de zichtbaarheid van excellentieonderwijs op evenementen zoals onderwijsdagen.

- Voor de zichtbaarheid van excellentieonderwijs is centrale coördinatie van excellentieonderwijs gewenst.

- Verzamel en verspreid actief informatie over good practices met betrekking tot innovaties, uitstraling, en uitstralingseffecten.

- Zorg ervoor dat kennis over innovaties niet enkel bij de betrokkenen blijft; maak kennis expliciet, door praktijken schriftelijk vast te leggen en te delen binnen de organisatie. 
- Communityvorming onder (honours)docenten kan gestimuleerd worden door activiteiten te organiseren rond relevante thema's, bijvoorbeeld rond de Sustainable Development Goals of specifieke onderwijsmethoden.

- De zichtbaarheid van excellentieonderwijs en de uitstralingseffecten die daarvan af komen zijn belangrijk voor de legitimiteit van excellentieonderwijs. De toegevoegde waarde moet zichtbaar worden gemaakt. Dit kan ook aan de hand van verhalen van docenten en studenten (user stories). Successen kunnen ook anders zichtbaar worden gemaakt, bijvoorbeeld via prijzen, manifestaties, festivals, onderwijsdagen, etc.

- Beleidsdoelen, zoals proeftuin en het creëren van een 'excellentiecultuur' worden niet altijd herkend door practitioners. Het gaat hier om een beleidswerkelijkheid, die niet per se op de werkvloer wordt gevoeld. Op de werkvloer gaat het meer om de studenten, dan om de toegevoegde waarde voor de instelling.

- De extrinsieke motivatie van studenten bij aanvang van het excellentieonderwijs kan veranderen in intrinsieke motivatie als ze eenmaal bezig zijn met excellentieonderwijs en gegrepen worden door de inhoud.

\section{Studenten:}

- Selecteurs voor excellentieprogramma's vinden vooral motivatie, denkvermogen en doorzettingsvermogen belangrijke kenmerken voor honoursstudenten. Verder vergroten buitenlandervaring, vrijwilligerswerk, een studiegerelateerde bijbaan en een cijfer boven het gemiddelde de kans dat je geselecteerd wordt voor deelname aan excellentieprogramma's.

- Dit onderzoek laat zien dat studenten in excellentieprogramma's dezelfde groei doormaken als reguliere studenten, maar dit betekent niet dat honoursstudenten geen voordeel ondervinden van hun deelname aan excellentieprogramma's. We adviseren studenten om maximaal te profiteren van excellentieonderwijs door vooral de disciplinaire diepte in te gaan. Probeer in het bijzonder kennis binnen of buiten je eigen discipline op te doen. Zo maak je optimaal gebruik van het extra onderwijs dat jouw hogeschool of universiteit aanbiedt.

- Hou je timemanagement goed in de gaten: studenten met een bijbaan vallen vaker uit.

- Als je tijdens je studie een buitenlandervaring, bestuurservaring of excellentieonderwijs hebt gedaan, zet dit dan vooral op je cv. Leg - net als bij andere ervaringen goed uit wat je hebt gedaan (specifieke onderwerpen), wat je hebt geleerd, waarom je het gedaan hebt, en wat je ermee wilde bereiken. Denk ook over deze aspecten na voordat je je committeert aan een van deze keuzes. Een heldere omschrijving bijvoorbeeld op Linkedln - maakt het makkelijker om op te vallen.

- De bekendheid van excellentieonderwijs bij werkgevers kan indirect gecreëerd worden door te laten zien wat je hebt geleerd.

- Het is aan te raden om een onderwijskeuze te maken met een bepaald doel voor ogen. Doe vooral iets dat bij je past, en ook bij het profiel waar je mee de arbeidsmarkt op wilt. Bijvoorbeeld excellentieonderwijs voor een academische carrière, een stage in het buitenland om je in een bepaald onderwerp te verdiepen, of bestuurs- 
ervaring om je leiderschapsvaardigheden te vergroten. Overweeg ook of je profiel onderscheidend genoeg is van medestudenten.

- Werkgevers vinden extra activiteiten naast studies interessant, dus in de selectiefase kan je hier vragen over verwachten.

- Je netwerk is belangrijk bij het vinden van een baan, zorg dus dat je netwerk wordt vergroot, zeker ook via een buitenlandervaring, bestuurservaring of excellentieonderwijs. 
